\title{
Evaluating the tracking e-files prototype project based on the task technology fit model
}

\author{
Nassir Jabir Al-khafaji ${ }^{1}$, Riyad Mubarak Abdullah ${ }^{2}$, Mohammed A. Kashmoola ${ }^{3}$ \\ ${ }^{1}$ Technical Institute Nasiriyah, Southern Technical University, Iraq \\ ${ }^{2-3}$ Department of Computer Science, University of Al-Hamdaniya, Iraq
}

\begin{tabular}{l} 
Article Info \\
\hline Article history: \\
Received Apr 25, 2019 \\
Revised Jun 26, 2019 \\
Accepted Jul 10, 2019 \\
\hline Keywords: \\
Educational institution \\
E-file tracking \\
Employee \\
SEM-PLS \\
Technology fit Model
\end{tabular}

\begin{abstract}
Locating files in an exact time is considered one of the greatest problems and the tedious process in universities nowadays. This problem becomes greater when the university has a large number of departments and transactions, as well as the documents are moving from one department to another. Especially, developing countries that have many problems and unstable environment and that may lead to lost or damage the important documents that influence on the decision making. Furthermore, the traditional manner not only wasted the time and energy, but also the paper cost for printing copies of required file. And with the advancement of technology and the increase of Internet users, documents are still being sent in Iraqi universities manually between departments. Although the higher education and scientific research ministry was recommended the public universities for using modern technologies during the daily transactions between the departments or amongst the units. Therefore, this study sought to design and evaluate the prototype system which tracks movements of the documents from one department to another as well as check the completion rate for each department. For providing opportunities to assess how well the use of e-file tracking system meets the needs of management units in universities. The systems implementation research notes the need to fit between tasks, technologies and users. Thus, this empirical study utilized the task technology fit model for this purpose. The results from selected participants indicated that all the factors significant effect on the employee's performance in E-file Tracking System, excepted, task characteristics. This study will be contributed to reduce the corruption and enhance the transparency and help the decision-makers make the right decision at the right time.
\end{abstract}

Copyright $@ 2020$ Institute of Advanced Engineering and Science. All rights reserved.

\section{Corresponding Author:}

Nassir Jabir Al-khafaji,

Southern Technical University,

Technical Institute Nasiriyah,

Baghdad Street, ThiQar.

Email: nassir.farhan@stu.edu.iq

\section{INTRODUCTION}

The advancement of Information and Communication Technology (ICT) results in development of many software application systems in various disciplines, such as telemedicine systems [1], electronic commerce systems [2] and e-voting [3]. These modern techniques have helped to provide good and accurate services to citizens and customers. With regard to Universities, it often includes a huge amount of physical file in shape of documents which carries very crucial and sensitive data on educational records. These sensitive data need protection to ensure that they transfer from one department to another without damage or knowledge of content. According to Romaniuk [4] dissemination of information in correct flow and the knowledge sharing mechanisms have vital role in every institution to manage their tasks. 
The changing role and the large amount of information prepared by department in university makes it necessary to apply tools which allow quick and efficient processing and use of such data safety. Information and communication technologies act as main supporting element that assists in the integration of institutions and increase possibilities for the cooperation between public administration bodies with other entities and departments. These information and technologies are becoming more and more helpful increasing the effectiveness of communication process [5]. In this study, used the term documents which mean to be files as well as papers throughout the article.

According to Goodhue and Thompson [6], the linkage between information and communications technologies and user performance has been an ongoing concern in IS research, this argument also supported by Carter, Petter and Randolph [7]. Moreover, although IS project in general and e-file systems in specific have been widely implemented in governments worldwide but the challenges faced by the users during and post-implementation of these systems remain a growing concerns for stakeholders.

The e-file Tracking System (EFTS) utilized in universities as a solution to traditional file management system and to improve the document management online. This makes the retrieval of documents online at with updated information on movement of files between offices in universities [8]. For all the potential benefits of using the e-file tracking system in the government universities, there are enormous challenges present when implementing it, with a failing in the implementations of electronic systems in developing countries and especially in Iraq, Because Iraq has experience in failure in many IT projects such as e-government local project [9]. In addition to that, Kvon et al [10] affirmed that rapid development in information technology and its usage in higher education contributes in efficiency but on the hand results in various risks that affect implementation of other educational processes and aspects of education system. These risk associated with using information technology in higher education suggests to examine the use of an electronic system by a person but also the effect bring by this system on employees job performance. Whereas, the abilities of employees to handle these information technology systems and the challenges in the implementation stages also serves as critical [11]. In light of the cited literature, the research to understand the factors that contributes in use of new system and employee job performance followed by an implementation in initial phase can be valuable to the universities. The best model to theoretically support the idea is task-technology fit (TTF) model. Lu and Yang [12] asserted that TTF model is widely used model that provides best theoretical explanation on how information technology leads to superior performance and impact of its usage by the employees. The rest of this paper is organized as follows: Section 2 highlights on the critical issues pertinent on the modern technology and the effect on the job performance. Section 3 elaborates TTF model as the related theoretical framework on the e-file tracking. Section 4 build the e-file tracking prototype for university working style by using Bootstrap Framework and PHP with MySql as the back-end programs language. Section 5 explains the methodology employed in current research including research design, study setting, instruments, data sample, data analysis technique employees, prototype system and experimental results. In addition, Section 6 contains the discussion and conclusion.

\section{STATEMENT OF THE PROBLEM}

To locate the specific file in a specific time is considered one of the most tiresome works in almost all the public organizations [13]. With the increasing number of departments in universities, file tracking requires an independent employee in almost all departments of the university. Time is wasted only for searching of a certain documents, and the problem becomes worse when the files or reports are important and may influence on the decision-making [14]. As well as, managing data is a laborious job; especially in cases where there is need to handle a large amount of data [15]. Therefore, Mahmood and Okumus [16] added that, electronic document system is currently becoming one of the most required tools for management in Universities. With the advancement of technology and the increase of Internet users, documents are still being sent in Iraqi universities manually between departments [17]. Although the higher education and scientific research ministry was recommended the public universities for using modern technologies during the daily transactions between the departments or amongst the units.

Notwithstanding that the benefits of the e-file system are numerous, there are significant challenges associated with developing and implementing it in many organizations. According to Zhu and Kindarto [18], the rate of failure of IT projects in the public sector is abnormally high in many countries (whether developed or developing countries), particular in post-implementation. The current empirical research recognized TTF model as powerful model and employed it to assess the adoption and use of an innovative artifact in a specific context in post-implementation stage. Goodhue and Thomson [6] argued that for any technology the willingness or acceptance from the users is very important and the technology should fit with task of the users to prove its effectiveness. In addition of the previous arguments, there is not much research, however, that focus specifically focuses on the Middle East and provides a richer understanding of the e-file tracking 
process and its challenges in public universities. Furthermore, so far, there is insufficient research on the study of system tracking acceptance or adoption based on the application of the TTF model

\section{REVIEW OF RELATED LITERATURE}

In this section, we discuss the key concepts and related works on the e-file concept and previous studies that concentrates on the system tracking.

\subsection{What is EFTS}

Electronic File Tracking System (EFTS) is "a web application that manages the movements of files at any time from one desk/room to another and assists in managing the efficient flow of files". Saldon-Eder [19] documented file tracking system as a system that manage the process of storing, locating, updating and sharing data file to support workflow progression and business outcomes. Sprague [14] added that, this application save paper, speed up communications and increase the productivity of business processes through its effectiveness to manage communication.

Using this system any desk/room can send and receive request, and decisions at any time. This file tracking system use a systematic procedure and assign file a unique numbering for efficient file management that use for file status monitoring and file movement tracking. This system uses a very powerful search form that can locate and file and also enable to analyses the file movement from one place to another. Therefore, Mahmood and Okumus [16] argued that in order to have effective management and administration system it is crucial for every organization to adopt an electronic document system.

In context of university, this system allows the administrator (Rector of a university) to create faculties and assign them all the departments based on the hierarchy of that particular university. Every department must have a user (chief of department) responsible for managing that department files. On the other hand, administrative have rights to add a user (Administrative Staff) who act a Secretariat of university in the file management system. All parties in the system including administrator and users can create a custom file (for instance: request or decision) and send them to concerned person for confirmation. As the file will be sent to the concerned person, the person will het notification of new arrived file and have an option to accept or reject the upcoming file. In case file is accepted no additional comment is require, on contrary a rejection require reasons for rejection of file and rejected file will be automatically returned to the sender. The accepted file will be moved to the accepted file section and provide options to the receivers like forward, send to archive, print, download and edit. In case of using "forward" option, the sender will see another window with possible forwarding's. As the work on file is finished, the responsible person can press the send for archiving button and file will be sent to the administrator for archiving. Moreover, same file is available for download and print option. Importantly, only accepted files can be edited by the responsible persons. In addition, only administrative have the right to see the movement history of the file archived in database.

\subsection{Benefits of File Tracking System}

According to Krasniqi [20] there are more advantages of using information technology in general and electronic file tracking system in specific for the organizations and universities, below listed the key benefits of such technologies:

a) Effective and efficient file management system Online File Tracking

b) Secure file management with fast retrieval

c) Staff performance improvement

d) Increase in organizational efficiency level

e) Paperless communication system and reduce paper cost

f) Less energy consumed in terms of resources

g) Time saving

h) No file redundancy

i) Less chances of mistakes in record keeping

j) Low cost and effective solution to tradition file management system

\subsection{E-file System Tracking in University}

Information and communication technologies have been implemented in different organizations for effectiveness. These technologies help organizations in many aspects such as strategy, budget, anticorruption, security and privacy, user requirements, cooperation and system integration among others [21]. Alshibly [22] also supported the claim and mentioned that information technologies are source of achieving efficiency in operations by reducing cost, automation in processes, improving capacity, minimizing errors 
and saving on labor cost. Özdemirci [23] indicated that the use of information and communication technology is essential and crucial for educational institutions. EFTS provides solution in terms of improved efficiency of communication by providing online tracking of the movement of document online and details of in and out of the offices.

Currently, most of the public universities in Iraq use a physical standard way for making decisions and requests or any important information. Similarly, Mushhad, Gilani, Ahmed and Abbas [24] said that most of universities are suffering due to obstacles in file management due to using paper based or semiautomated systems. Other than this during the archiving of needed file, they have to use physical standard way [20]. Most often, the archiving of the files should be done alphabetically or numerically. This traditional way requires lot of energy and a time consuming method, it can be result in misplacing of files or sometime even loss of important file that can be hinder for university work and could decease the work performance. In case when university wants to solve an issue or make a decision based on the file that is available in the physical archive, this is a time consuming process to go and find such file from the archive room. All these activities results in wastage of time and energy which can be utilized for other organizational processes. Mushhad et al., [24] referred that, as indexing multiple documents in universities, searching and sorting are cumbersome processes for paper documents.

On the other hand, seldom situation is file lost and to secure a file room it also cost too much to organization. All security systems including sensors, anti-theft alarms, fire alarms and security devices cost organization a heavy amount. In case of country like Iraq with unstable situation, a file can be missing or lost due to corruption. These all way of storing file allow unauthorized person to access and modify the record, even the person can torn or burn the file and the record will be vanished forever. In fact, these kinds of situations can be serious problem when the record is of sensitive nature. These problems and others (see Section 2) encourage the current research to develop a file tracking system that can solve all discuss problem which can occur due to physical file system and solve these problems in best manner and assess this new file system based on TTF model perspective. According to Demong, Hassan, Besar and Zulkifli [8], electronic file tracking is becoming more crucial for university because of their aim of paperless society and helping staff in delivering, maintaining and managing all the documents efficiently in order to provide excellence service quality. Furthermore, EFTS appears as solution that provides improved efficiency in retrieving documents online at any time and also keeps track of the movement of files from one place to another [19].

Electronic file transfer system brings many benefits to university which includes the availability of the document immediately and these documents are available to multiple users at the same time. This also eliminates the need of extra copies for the others and electronic documents will not get lost if they are indexed and backed up properly. Williams and Uzochukwu [25] stated that, document tracking system is a cost effective web-based application that will guarantee organization savings on an on-going basis. Moreover, improve customer service across all departments including enrollment services. Therefore, based on above the current study aimed to design and develop and electronic e-file tacking system that can be used by universities with purpose to move from traditional file system to an organized and cost saving electronic system, the system is then evaluated based on TTF perspective.

\subsection{Tasks-Technology-Fit (TTF)}

This section highlights the importance of information technology and how the fit between modern technologies impact on employees' task in achieving individual performance. To achieve this main objective, the prior study asserted that, the task-technology fit is authentic source and can be used as a diagnostic tool to assess whether information technologies system and services used by a give organization meets the user needs or in other words failed to provide the require support. According to Goodhue and Thompson [6] TTF is "the degree to which a technology assists an individual in performing his or her portfolio of tasks". Moreover, Lu and Yang [12] documented TTF as a theoretical model that is widely employed to assess how information technology leads to superior performance and usage impact. Figure 1 present the TTF model as depicts that both task characteristics and technology characteristics affect the task technology fit, which in turn determines individual performance and actual utilization.

Although TTF model has well known and widely adapted in information system research filed by various researchers such as D'Ambra, Wilson and Akter [26], Junglas, Abraham and Watson [27] and Zhou, $\mathrm{Lu}$, and Wang [28]. But the limited attention has been paid on applying TTF in electronic file tracking system as used in current research. The claim has been supported by Lu and Yang [12], where the use of TTF model has been recommended to further explore TTF and validate it in various contexts. Based on the identified gap, the current research used TTF as an established theoretical framework in information system research that allows investigation of issues of fit of technology to tasks as well as performance (source). TTF explores the relationship between individual tasks and technology fit profiles by measuring user performance and technology utilization. Table 1 lists the TTF constructs with brief description for each one. 


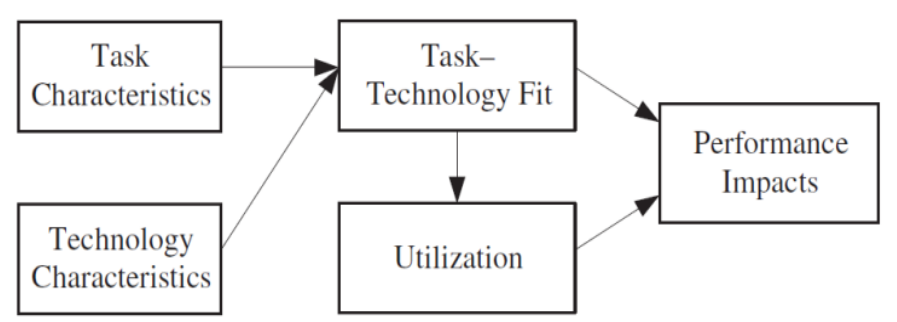

Figure 1. The task-technology fit model

Table 1. TTF Constructs

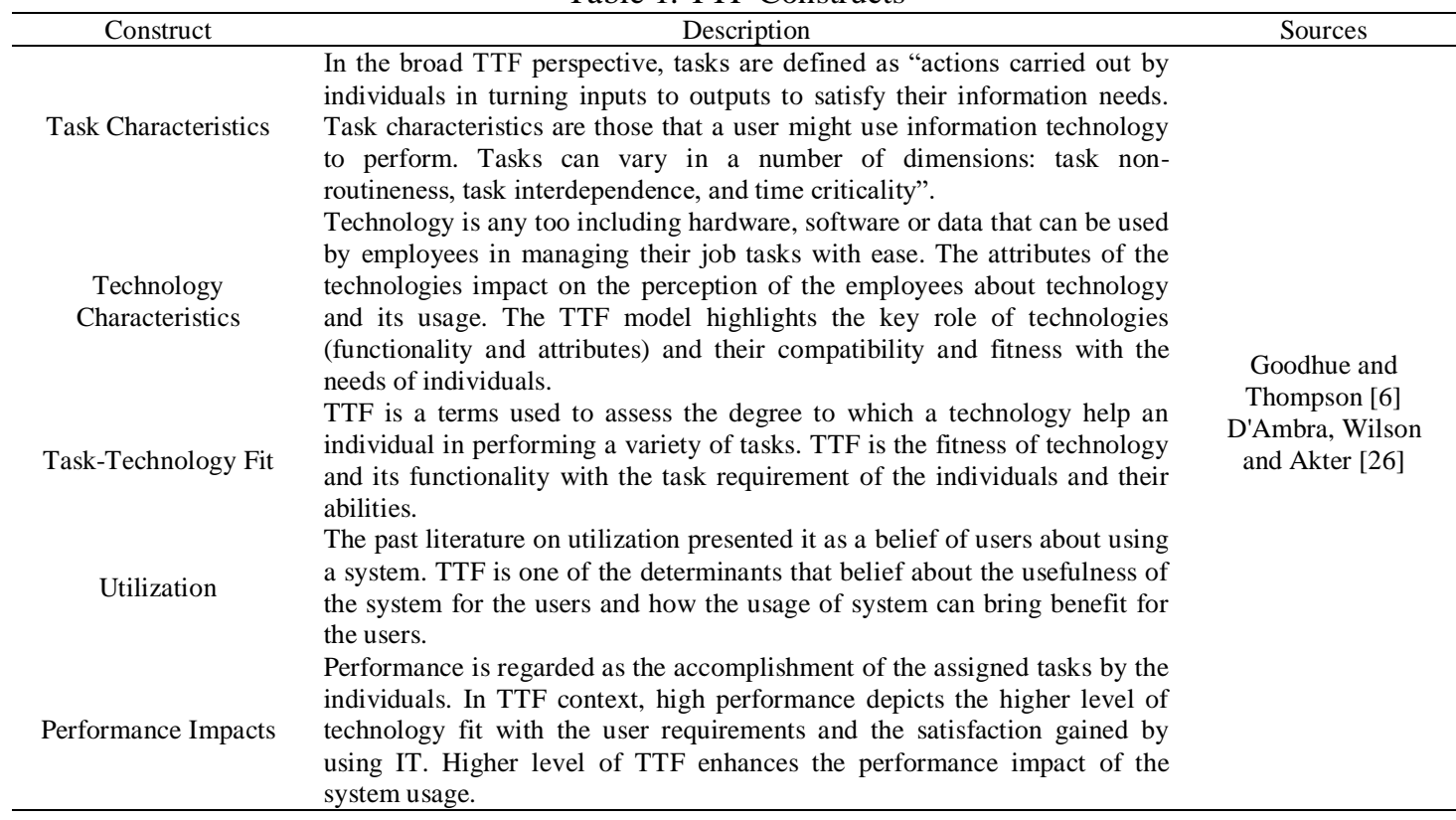

\section{DEVELOPING THE E-FILE TRACKING SYSTEM PROTOTYPE}

Electronic file has been proposed as a solution prototype system to enhance the efficiency of retrieving the significant documents and reports online at anytime and anywhere as well as tracing the movement of documents in and out of the specific department.

The softwares used to develop this system are WAMP and Sublime Text v3.0. The researchers also used frameworks such as Bootstrap. According to Saldon-Eder [19], Bootstrap is one of the most popular front-end frameworks and open source projects in the world. It is a front-end framework for faster and easier web development. The researchers chose Bootstrap because it is easy to learn and can be easily be manipulated. Since web-based programs and software are easy to access, HTML and PHP are good for developing this kind of programs. HTML and PHP also allows the researcher to do more designs with the help of Bootstrap. MySQL is a free and open source database program. It can be used to create, modify and manipulate information contained in the database. It is used to add, delete and update information in the database. Figure 2 illustrates the main functions of this system.

In order to achieve the proposed system, the researchers developed functional software that satisfied the system design. The researchers also used some logical procedures in creating and developing the software in order for the system to work efficiently. The researchers chose Hypertext Processor (PHP) and Hypertext Mark-up Language (HTML) for the front-end, PHP/HTML as a front-end for our proposed system because it has the features which suites the needs of our client and we can assure that it is user-friendly. 


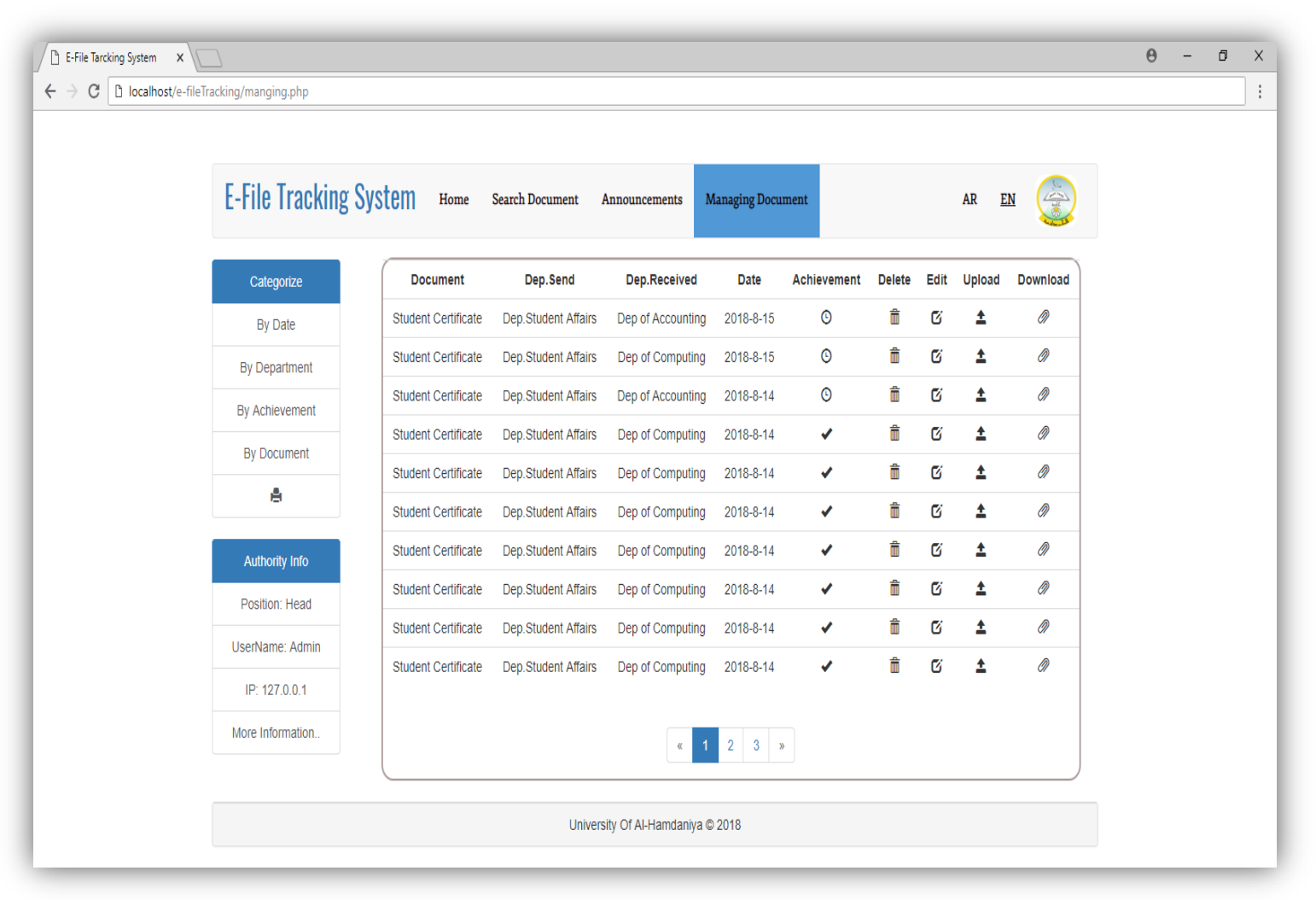

Figure 2. Managing page for admin

\section{MEASURING E-FILE TRACKING SYSTEM BASED ON TTF}

The current research employed quantitative research design, where survey questionnaire was used as a source of primary data collection. The survey questionnaire was carefully designed in accordance with previous literature and distributed and filled by target participants who have experience in using selected system which is e-file tracking system. Moreover, the purpose of this study understands the fit between the technologies used and the employee's performance.

Meanwhile, to evaluate the fit of e-file tracking system on the employee tasks and performance, this study harnesses the structural equation modeling techniques (SEM) for this purpose. More specifically, SEM using Partial Least Square (PLS) has been opted to run the proposed model. PLS is a regression based technique based on path analysis to test the proposed hypothesis. The PLS approach is more appropriate to employed in current research as compared to other SEM approaches. The reason of selection PLS is the flexibility of normality data assumption, small sample size requirement and ability to handle complex predictive model. The PLS approach is employed using computer program named SmartPLS 3 which is widely used in multivariate data analysis. In addition, the survey measures five ordinal variables, which are Technology Characteristics, Task Characteristics, Task-Technology Fit, Utilization and Performance Impacts, as well as demographic dimensions. The measurements for the focal constructs were adapted from the previous research studies in the field as indicted in Table 2. The selected measures used in current research were carefully adapted from the previous literature in filed due to their authenticity, usefulness and relevance with current research. Table 2 presents the summary of the instruments used in current research, their sources and proposed hypotheses. 


\begin{tabular}{|c|c|c|c|c|}
\hline Constructs & Items & NO. & Hypothesis & Adopted from \\
\hline $\begin{array}{l}\text { Task } \\
\text { Characteristics } \\
\text { (TASK) }\end{array}$ & $\begin{array}{l}\text { TASK1 - I need to manage my } \\
\text { accounts (the documents) } \\
\text { anytime anywhere } \\
\text { TASK2 - I need to make } \\
\text { transfers (traces the documents) } \\
\text { anytime anywhere } \\
\text { TASK3 - I need to acquire } \\
\text { document information in real } \\
\text { time. }\end{array}$ & H1 & $\begin{array}{l}\text { Task characteristics } \\
\text { positively affect the } \\
\text { perceived task-technology } \\
\text { fit in e-file system. }\end{array}$ & \\
\hline $\begin{array}{l}\text { Technology } \\
\text { characteristics } \\
\text { (TECH) }\end{array}$ & $\begin{array}{l}\text { TECH1 - e-file tracking system } \\
\text { provides ubiquitous services } \\
\text { TECH2 - e-file tracking system } \\
\text { provides real time services } \\
\text { TECH3 - e-file tracking system } \\
\text { provides a quick service } \\
\text { TECH4 - e-file tracking system } \\
\text { provides secure services. }\end{array}$ & H2 & $\begin{array}{l}\text { Technology characteristics } \\
\text { positively affect the } \\
\text { perceived task-technology } \\
\text { fit in e-file system. }\end{array}$ & \\
\hline $\begin{array}{l}\text { Task technology fit } \\
\text { (TTF) }\end{array}$ & $\begin{array}{l}\text { TTF1 - In helping complete my } \\
\text { tasks, the functions of e-file } \\
\text { tracking system are enough. } \\
\text { TTF2 - In helping complete my } \\
\text { tasks, the functions of e-file } \\
\text { tracking system are appropriate. } \\
\text { TTF3 - In general, the functions } \\
\text { of e-file tracking system fully } \\
\text { meet my university needs }\end{array}$ & H3a & $\begin{array}{l}\text { Task-technology fit in e- } \\
\text { file system has a positive } \\
\text { impact on Performance } \\
\text { Impacts }\end{array}$ & $\begin{array}{l}\text { Zhou et al. [28] } \\
\text { Lin and Huang [29] } \\
\text { Goodhue and } \\
\text { Thompson [6] }\end{array}$ \\
\hline Utilization & $\begin{array}{l}\text { UTILIZ1 - I use e-file tracking } \\
\text { system } \\
\text { UTILIZ2 - I use e-file tracking } \\
\text { system to manage my tasks } \\
\text { UTILIZ2 - I use e-file tracking } \\
\text { system to tracking the } \\
\text { documents }\end{array}$ & H3b & $\begin{array}{l}\text { Task-technology fit in e- } \\
\text { file tracking system has a } \\
\text { positive impact on using e- } \\
\text { file tracking system. }\end{array}$ & \\
\hline $\begin{array}{l}\text { Performance } \\
\text { Impacts (PI) }\end{array}$ & $\begin{array}{l}\text { PI1 - I gain time using } \\
\text { electronic tracking system } \\
\text { PI2 - electronic tracking system } \\
\text { allows me to make my work } \\
\text { quicker } \\
\text { P13-I feel e-file tracking system } \\
\text { is useful }\end{array}$ & H4 & $\begin{array}{l}\text { Utilization of e-file } \\
\text { tracking system has a } \\
\text { positive } \begin{array}{l}\text { impact } \\
\text { Performance Impacts. }\end{array}\end{array}$ & \\
\hline
\end{tabular}

\section{MEASUREMENT MODEL TESTING}

The current research used measurement model to assess the reliability and validity of the constructs employed. As suggested by Chin [30] and Hair et al. [31], the reliability and validity of construct are assessed through composite reliability, discriminant validity and convergent validity in current research. The reliability of the reflect measurement model using PLS-SEM should be assessed through indictor reliability and construct reliability as show in Figure 3. The agreed criterion of factor loading greater than 0.70 [32-34] was used to assess the indicators reliability and the loading on its associated latent construct was checked. The current research used PLS Algorithm in SmartPLS to assess the measurement model.

As per suggestions of Hair et al. [35] those indicators with loading between 0.4-0.7 can be deleted where it improves the values of Composite Reliability (CR) or Average Variance Extracted (AVE) to gain acceptable thresholds. In current research measurement model, indicator TECH1 less than 0.7 but meanwhile $\mathrm{CR}$ and AVE are acceptable, therefore this indicator is retained. In order to measure the convergent validity of the used constructs, CR and AVE were used based on previous literature. In this regard, Fornell and Larcker [36] provided a threshold where CR of each construct used in measurement model should be greater than 0.7 and the value of AVE should be above 0.5 to ensure the constructs hold convergent and discriminant validity. The measurement model in current research shows that CR an AVE for the used construct are above the threshold suggested by Fornell and Larcker [36].These results are presented in Table 3.

Chin [37] mentioned the criteria for establishment of discriminant validity in which square root of AVE is greater than correlation shared between constructs and others constructs in the model. The greater value of square root of AVE depicts that constructs hold the discriminant validity. The result in Table 4 shows that current research meets Fornell and Larcker [36] criteria. The values on diagonal depict the constructs hold discriminant validity. 


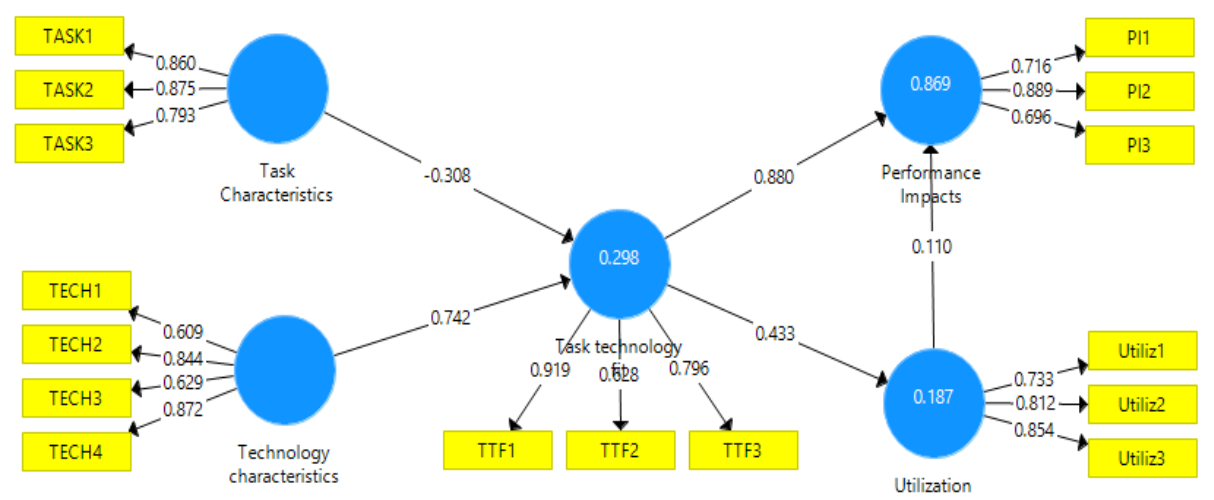

Figure 3. Measurement model

Table 3. The Results of Assessment of the Measurement Model

\begin{tabular}{ccccc}
\hline Constructs & Items & Loading & CR & AVE \\
\hline \multirow{3}{*}{ PI } & PI1 & 0.716 & & \\
& PI2 & 0.889 & 0.814 & 0.596 \\
& PI3 & 0.696 & & \\
TASK & TASK1 & 0.860 & & \\
& TASK2 & 0.875 & 0.880 & 0.711 \\
& TASK3 & 0.793 & & \\
& TECH1 & 0.609 & & \\
TECH & TECH2 & 0.844 & 0.829 & 0.624 \\
& TECH3 & 0.629 & & \\
& TECH4 & 0.872 & & \\
& TTF1 & 0.919 & & 0.560 \\
& TTF2 & 0.628 & 0.832 & \\
& TTF3 & 0.796 & & 0.642 \\
& UTILIZ11 & 0.733 & & \\
\hline
\end{tabular}

Table 4. Discriminant Validity of the Variable Constructs

\begin{tabular}{cccccc}
\hline Latent Variables & 1 & 2 & 3 & 4 & 5 \\
\hline PI & $\mathbf{0 . 7 7 2}$ & & & & \\
TASK & 0.353 & $\mathbf{0 . 8 4 3}$ & & & \\
TECH & 0.927 & 0.255 & $\mathbf{0 . 7 9 0}$ & & \\
TTF & 0.650 & 0.760 & 0.508 & $\mathbf{0 . 7 4 8}$ & \\
UTILIZ & 0.490 & 0.529 & 0.433 & 0.697 & $\mathbf{0 . 8 0 1}$ \\
\hline
\end{tabular}

\section{STRUCTURAL MODEL TESTING}

The current research in addition to PLS Algorithm used bootstrapping procedure to get the decision values, where $\mathrm{T}$-values and $\mathrm{P}$ values for all the path were produced to support the decision either hypothesis is supported or not supported. Table 5 provides details on the test paths, $t$-vlaue, p-value and decision regarding the hypothesized relationship.

Results of structural model for hypotheses testing indicated that out of five of the exogenous and endogenous latent variables, one of the variables was not supported, namely: Task Characteristics-> Tasktechnology fit, where t-value was 1.576 .

Table 5. Hypotheses Testing Results

\begin{tabular}{ccccc}
\hline NO. & Hypothesis & t.value & p.value & Decision \\
\hline H1 & $\begin{array}{c}\text { Task Characteristics -> Task } \\
\text { technology fit }\end{array}$ & 1.576 & 0.116 & $\begin{array}{c}\text { Not } \\
\text { supported }\end{array}$ \\
H3a & $\begin{array}{c}\text { Task technology fit -> Performance } \\
\text { Impacts }\end{array}$ & 18.783 & 0.000 & Supported \\
H3b & $\begin{array}{c}\text { Task technology fit -> Utilization } \\
\text { Technology Characteristics -> Task }\end{array}$ & 4.133 & 0.000 & Supported \\
technology fit & 3.685 & 0.000 & Supported \\
H4 & Utilization-> Performance Impacts & 1.645 & 0.100 & Supported \\
\hline
\end{tabular}


The values of $\mathrm{R}^{2}$ for the constructs Performance Impacts, Task-technology fit and Utilization are acceptable and adequate. Where, $\mathrm{R}^{2}$ of key target construct of the present study (employee's performance of e-file tracking system) has a high value of 0.869 . In the same context, the $\mathrm{R}^{2}$ for each of Task-technology fit (0.298) and Utilization (0.187) provides acceptable level of explanation. The present study also supports the prior finding through the use of $\mathrm{Q}^{2}$ predictive relevancy measure, as shown in Table 6.

\begin{tabular}{cllcccc}
\multicolumn{7}{c}{ Table 6. Results of $\mathrm{R}^{2}, \mathrm{Q}^{2}$, and $f^{2}$} \\
\hline Construct & $\mathrm{R}^{2}$ & $Q^{2}$ & Correlation Between variables & $f^{2}$ & Remarks \\
\hline Performance & 0.8 & 0.4 & Technology characterizes - & Large \\
Impacts & 69 & 36 & >Performance Impacts & Medium \\
Task- & 0.2 & 0.3 & Technology characterizes -> Utilization & 0.230 & Medium \\
technology fit & 98 & 69 & Task technology -> Task-technology fit & 0.331 & Medium \\
Utilization & 0.1 & 0.3 & The & Utilization ->Performance Impacts & 0.220 & \\
\hline
\end{tabular}

The blindfolding procedure using SmartPLS provides $Q^{2}$ value with an omission distance $D=7$ show the adequate predictive relevance for Performance Impacts (0.436), Task-technology Fit (0.369) and Utilization (0.387). The finding indicates that the value of $\mathrm{Q}^{2}$ is above zero which is criterion to show predictive relevance of the path model. The values calculated for effect size using $f^{2}$ also provide support for variables (Technology characterizes, Task characterizes and Utilization). The $f^{2}$ a value in Table 6 indicates that the effect Technology characterizes->Utilization, Task technology -> Task-technology fit and Utilization ->Performance Impacts is medium. Moreover, the effect of Technology characterizes ->Performance Impacts is large.

\section{CONCLUSION}

Information and communication technologies have been implemented in different organizations for effectiveness. These technologies help organizations in many aspects such as strategy, budget, anticorruption, security and privacy, user requirements, cooperation and system integration among others. With regard to universities, centralized data storage and sharing system within specific servers assist university departments to access information with ease in efficient and effective manner. Moreover, it provides the important documents a secure storage and retrieval place. Therefore, the electronic file Tracking System is developed to assist the monitoring of documents specifically in the processes of tracking the completion of transactions and keeping files required in decision-making. The TTF model is considered as an important theoretical contribution in understanding how utilization of informational technology impacts performance of individuals. This current research employed TTF model to determine the factors that influence on individual the individual performance of e-file tracking system.

Data was gathered in this study from staffs who work in the university in Mosel, Iraq. Based on the analysis of the collected data, task-technology fit has a significant relationship with Performance Impacts and Utilization. Meanwhile, Technology Characteristics has a significant relationship with Task-technology fit and Utilization also significantly affects employee's Performance on e-file tracking system. While, Task Characteristics does not affect Task technology fit.

This prototype system aims to manage and preserve the important documents related to educational institutes in the higher education through web-based system. This system will enable the chief stakeholders to easily access and retrieve the document when needed. Moreover, this system provides a central repository system for the documents and streamlines document process through a department. This system also provides a tracking system and well organized monitoring system which is one of the key features in an e-file tracking prototype.

\section{REFERENCES}

[1] J. A. Villanueva, et al., "The role of telemedicine and mobile health in the monitoring of sleep-breathing disorders: improving patient outcomes," Smart Homecare Technology and TeleHealth, vol. 4, pp. 1-11, 2017.

[2] H. Kojima, et al., "Web Service Systems for Cooperative Work Support in Knowledge Creation Processes," Human Interface and the Management of Information. Designing Information Environments, pp. 94-103, 2009.

[3] E. Aljarrah, et al., "E-voting in Jordan: Assessing readiness and developing a system," Computers in Human Behavior, vol. 63, pp. 860-867, 2016. 
[4] P. Romaniuk, "Electronic administration as a factor in the efficient management, development and communication of public administration," International Journal of Contemporary Management, vol. 2016, pp. 79-94, 2016.

[5] N. J. Al-Khafaji, et al., "Critical Variables that Impede Electronic Information Sharing: Administrator's and Lecturer's Standpoint," Journal of Engineering and Applied Sciences, vol. 13, pp. 1654-1662, 2018.

[6] D. L. Goodhue and R. L. Thompson, "Task-technology fit and individual performance," MIS quarterly, pp. 213-236, 1995.

[7] M. Carter, et al., "Desperately seeking information in information systems research," International Conference on Information System, 2015.

[8] R. Demong, et al., "Electronic Document Tracking System (EDTS): A Prototype," in Symposium on Human Interface, 2009, pp. 375-383.

[9] N. J. Al-Khafaji and H. H. Azeez, "The Utilization Of Information System Model For Assessing Digital Services" International Journal of Mechanical Engineering and Technology and Health Care, vol. 9, pp. 827-839, 2018.

[10] G. M. Kvon, et al., "Risk in Implementing New Electronic Management Systems at Universities," Eurasia Journal of Mathematics, Science and Technology Education, vol. 14, pp. 891-902, 2017.

[11] T. A. Sykes., "Support Structures and Their Impacts on Employee Outcomes: A longitudinal Field Study of an Enterprise System Implementation," Issues, vol. 11401, 2015.

[12] H.-P. Lu and Y.-W. Yang, "Toward an understanding of the behavioral intention to use a social networking site: An extension of task-technology fit to social-technology fit," Computers in Human Behavior, vol. 34, pp. 323-332, 2014.

[13] P. Vikash Kumar, et al., "File Tracking System," International Journal of Scientific Engineering and Applied Science (IJSEAS), vol. 1, pp. 195-200, 2015.

[14] R. H. Sprague Jr, "Electronic document management: Challenges and opportunities for information systems managers," MIS quarterly, pp. 29-49, 1995.

[15] J. D. F. Miñon, et al., "An Intranet-based Document Management and Monitoring System framework: A case for the National University Quality Management Office," in Region 10 Conference (TENCON), 2016 IEEE, 2016, pp. 2262-2267.

[16] A. Mahmood and I. T. Okumus, "Design and Implementation of an Electronic Document Management System," MAKÜ-Uyg, vol. 1, pp. 9-17, 2017.

[17] N. J. Al-Khafaji, R. M. Abdullah \& M. A. Al-Khafaji., "Evaluating the Tracking e-Files Prototype Project Based on The Task Technology Fit Model," 2018 The International Conference on Smart Instrumentation, Measurement and Application 2018 (ICSIMA), Thailand, 2018..

[18] Y.-Q. Zhu and A. Kindarto, "A garbage can model of government IT project failures in developing countries: The effects of leadership, decision structure and team competence," Government Information Quarterly, vol. 33, pp. 629-637, 2016.

[19] M. Saldon-Eder, "E-Document Tracking System," European Academic Research, vol. III, pp. 2731-2747, 2015.

[20] H. Krasniqi, "File Tracking System," Degree of Bachelor of Science, Faculty of Architecture and Engineering, Epoka University, Tirana, 2013.

[21] H. Abdulkadhim, et al., "A Research Framework of Electronic Document Management Systems (EDMS) Implementation Process in Government," Journal of Theoretical \& Applied Information Technology, vol. 81, 2015.

[22] H. Alshibly, et al., "Investigating the Critical Success Factors for Implementing Electronic Document Management Systems in Governments: Evidence From Jordan," Information Systems Management, vol. 33, pp. 287-301, 2016.

[23] F. Özdemirci, "Development and implementation of the document management and archiving system (BEYAS) for universities: an example of cooperation," pp. 225-235, 2008.

[24] S. Mushhad, et al., "Electronic document management: a paperless university model," in 2nd IEEE International Conference on Computer Science and Information Technology, 2009. ICCSIT 2009. pp. 440-444, 2009.

[25] E. Williams and O. C. Uzochukwu, "Electronic File Monitoring System," Global Journal of Pure and Applied Sciences, vol. 21, pp. 71, 2015

[26] J. D'Ambra, et al., "Application of the task technology fit model to structure and evaluate the adoption of Ebooks by A cademics," Journal of the American society for information science and technology, vol. 64, pp. 48-64, 2013.

[27] I. Junglas, et al., "Task-technology fit for mobile locatable information systems," Decision support systems, vol. 45, pp. 1046-1057, 2008.

[28] T. Zhou, et al., "Integrating TTF and UTAUT to explain mobile banking user adoption," Computers in Human Behavior, vol. 26, pp. 760-767, 2010.

[29] T.-C. Lin and C.-C. Huang, "Understanding knowledge management system usage antecedents: An integration of social cognitive theory and task technology fit, "Information \& Management, vol. 45, pp. 410-417, 2008.

[30] W. W. Chin, "Bootstrap cross-validation indices for PLS path model assessment," in Handbook of partial least squares, ed: Springer, pp. 83-97, 2010.

[31] J. F. Hair, et al., "The use of partial least squares structural equation modeling in strategic management research: a review of past practices and recommendations for future applications," Long range planning, vol. 45, pp. 320$340,2012$.

[32] J. F. Hair, et al., "PLS-SEM: Indeed a silver bullet," Journal of Marketing theory and Practice, vol. 19, pp. 139$152,2011$.

[33] J. Hulland, "Use of partial least squares (PLS) in strategic management research: A review of four recent studies," Strategic management journal, vol. 20, pp. 195-204, 1999.

[34] O. Götz, et al., "Evaluation of structural equation models using the partial least squares (PLS) approach," in Handbook of partial least squares, ed: Springer, pp. 691-711, 2010. 
[35] J. F. Hair Jr, et al., A primer on partial least squares structural equation modeling (PLS-SEM): Sage Publications, 2016.

[36] C. Fornell and D. F. Larcker, "Evaluating structural equation models with unobservable variables and measurement error," Journal of marketing research, pp. 39-50, 1981.

[37] W. W. Chin, "The partial least squares approach to structural equation modeling," Modern methods for business research, vol. 295, pp. 295-336, 1998.

\section{BIOGRAPHIES OF AUTHORS}
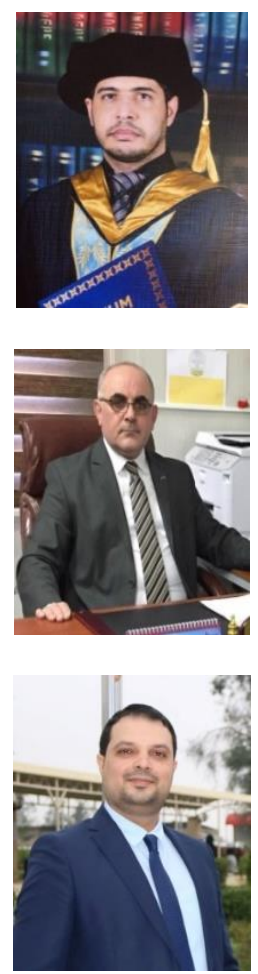

Dr. Nassir Jabir Al-khafaji is the Lecturer of Computers Systems Department at Technical Institute-Nasiriyah. He is the Manager of Computer Center at Technical Institute-Nasiriyah, Southern Technical University. He earned his MSc. in social networking platforms. His $\mathrm{PhD}$ was in e-government applications from the Utara University Malaysia in Malaysia. My research is in the area of e-Application (e-government, e-learning, etc), where I focus on electronic projects evaluation and testing and user behaviours. This has involved studying, designing, and evaluating a range of modern applications including e-voting, e-file, and IOT. My work tends to span many disciplines including computer science.

Dr. Riyad Mubarak Abdullah is the Dean of the College of Education at the University of Alhamdaniya. He is also an assistant professor and lecturer at the Department of Computer Sciences. He earned his MSc. in networking. His $\mathrm{PhD}$ was in image processing from the University of UGM in Indonesia. His main research interests are image processing, networking and electronic applications.

Mr. Mohammed A. Kashmoola is a lecturer at the Department of Computer Sciences the University of Alhamdaniya. He is also the manager of the universiry president's office. His main research interests are designing and testing electronic applications. 